\title{
Childhood Depression Can Impair Learning
}

\author{
José Carlos Rosa Pires de Souza1, Matheus Gonçalves Chaves Mello², \\ Bruno Massayuki Makimoto Monteiro, Vítor Cruz Rosa Pires de Souza², \\ Vitória Siufi Zandoná ${ }^{2}$ \\ ${ }^{1}$ Universidade Estadual de Mato Grosso do Sul (UEMS), Campo Grande, Mato Grosso do Sul, Brazil \\ ${ }^{2}$ Universidade para o Desenvolvimento do Estado e da Região do Pantanal (Uniderp), Campo Grande, Mato Grosso do Sul, Brazil \\ Email: josecarlossouza@uol.com.br, matheusmellochaves@hotmail.com, \\ brunoftmakimoto@hotmail.com,crpsvitor@gmail.com,vizandona@gmail.com
}

How to cite this paper: de Souza, J. C. R. P., Mello, M. G. C., Monteiro, B. M. M., de Souza, V. C. R. P., \& Zandoná, V. S. (2020). Childhood Depression Can Impair Learning. Creative Education, 11, 2014-2026. https://doi.org/10.4236/ce.2020.1110147

Received: September 25, 2020

Accepted: October 19, 2020

Published: October 22, 2020

Copyright $\odot 2020$ by author(s) and Scientific Research Publishing Inc. This work is licensed under the Creative Commons Attribution International License (CC BY 4.0).

http://creativecommons.org/licenses/by/4.0/ (c) (i) Open Access

\begin{abstract}
Depression is a worldwide public health problem that affects the quality of life in general at humans, especially children. This study aims to discuss the aspects in which this disorder compromises neuropsychomotor development and child learning. A narrative bibliographic review of the last 10 years (20102020) was carried out in the Medline, Pubmed, SciELO, Lilacs, Psycinfo and Periodical CAPES databases, using the keywords depression, depressive disorder, depressive episode, childhood, cycle vital, learning, learning and the Boolean AND. From the study, it is concluded that childhood depression reduces the capacity for logical reasoning, concentration and memory, delaying or interrupting the development of cognitive, psychomotor and learning skills. For this reason, it is essential that a correct diagnosis is made (e.g., using diagnostic manuals, such as Child Depression Inventory, International Classification of Diseases and Diagnostic and Statistical Manual of Mental Disorders), but also an effective treatment (both psychological and pharmacological).
\end{abstract}

\section{Keywords}

Depression, Childhood, Cognition, Learning

\section{Introduction}

Depression is known to cause not only illness and disability, but also suicide in some cases, being the second leading cause of death in people aged 15 to 29 years (Bernaras et al., 2019). According to studies, the prevalence of mental disorders in children and adolescents reaches up to $15 \%$ and depressive disorders is $2.6 \%$ among children and adolescents. In addition, it is estimated that, of approx- 
imately 1.8 billion subjects ( 5 to 19 years), more than 45 million have depressive disorders (Polanczyk et al., 2015).

Although such prevalence rates are increasing, mood disorders in childhood are still somehow neglected. Only after the 1970s they began to believe that children could become mentally ill due to their lack of a mature personality structure; and also due to the idea that childhood is a time of joy, happiness and lack of worries and responsibilities (Lima \& Mosmann, 2020). Among these psychic problems is depression, with all its psychopathological apparatus, which can compromise the child's learning process (Gomes et al., 2013).

Depression is an important public health problem, with neurochemical, psychological, social, environmental and spiritual impairments; this integral view of the human being must be taken into account both in the diagnosis, as well as in the treatment, which will assist in the prognosis of the clinical condition (Petresco et al., 2014). When it comes to children, the diagnosis and treatment are different from that of adults and the elderly, as well as the prognosis; childhood depression is more serious than you might think. In a first approach to children, their signs and symptoms have peculiar characteristics that are sometimes confused with other existential and mental problems. Hence the need to know well the so-called normal child neuropsychomotor development, in order to differentiate from what will be pathological. For that, it is necessary an anamnesis with the child and with his parents, caregivers and guardians; the latter often feel ashamed or guilty for the child's clinical condition and do not provide adequate information, thus impairing the approach and, subsequently, the treatment. Together, all of this interferes with the prognosis and impairment of the children's learning process, and may perpetuate the psychopathological picture for adult life (Lima \& Mosmann, 2020).

In view of the high rates as well as the repercussions that depression can have on learning, this article aims to discuss the aspects of child neuropsychomotor development and learning, which can be compromised by depression; depressive psychopathology interferes in many mental functions, such as memory, thought, sleep, appetite, affectivity, orientation, attention, among others, which are essential to the learning process.

\section{Method}

A quantitative research was done through a non-systematic narrative bibliographic review of articles from the last 10 years (2010-2020) in the Medline, Pubmed, SciELO, Lilacs, Psycinfo and CAPES journals databases, using the descriptors depression, depressive disorder, depressive episode, childhood, life cycle, learning and the Bolean "AND". All these materials were read in full, categorized and critically analyzed.

When starting the searches, those whose title and abstract did not share the scope and objective of the present study were excluded. After that, they were read and analyzed. As an effect, a line of narrative reasoning was drawn that en- 
compassed the theme; fact that resulted in the following topics: 1) "Child development and learning"; 2) "Diagnosis of depression in childhood"; 3) "Treatment of depression in childhood" and 4) "Child depression and learning".

The narrative type bibliographic review was chosen because it consists of a wide and appropriate type of publication to describe and discuss the development of a theme, or even its "state of the art". However, its strength of scientific evidence is considered low due to the fact that it is impossible to reproduce its methodology; however, they contribute to the debate of certain issues, raising questions and collaborating with knowledge in a short period of time (Rother, 2007).

\section{Result and Discussion}

\subsection{Child Development and Learning}

Childhood is seen as a phase of the vital cycle where dependence on the care of others, happiness and disengagement predominate; however, child development is primordial for the evolution of the human being. Since the first trimester of maternal pregnancy and also in early childhood are shaped the processes of brain architecture, through the interaction of genetic heritage and environmental factors in which the child lives. The healthier these conditions are, the neuropsychomotor development of that person, which cannot be considered a prototype or miniature adult (de Souza \& Veríssimo, 2015).

Considering the childhood from birth to 11 years of age, it can be said that, according to Jean Piaget, "it is proper to early childhood ( 0 - 4 years) not to recognize the moral issue (how I should act), that is, where the obligation to perform or avoid certain behaviors lies. Young children do not recognize the norms like there is something that must be avoided or realized according to the precepts of the law. Piaget called this phase an "anomie", the absence of a conception of the existing laws, norms or rules that coordinate social coexistence and the preservation of the rights of others. Children respect orders for fear of punishment and not because they understand the nature of the law. In second childhood, a phase of moral heteronomy ( 5 - 11 years), children recognize the law as an orderly source of behavior, but laws are made by someone very important and sovereign; the law is an externality, it comes from others" (Maciel et al., 2016). Therefore, the child understands that, in order to proceed with correction, he has to obey another human being superior to him. If this one does not have enough moral and cognitive content to give him a good education, he may have future problems in his personality. However, one should not fall into a social reductionism, because other factors will influence his development and his social relations.

In regards to the environment, it is much discussed that it plays a fundamental role in the existence and survival of any human being. Vigotski states that "what really matters to the scholar of child development is not the environment itself, but the way it acts and interferes in that development" (Pino, 2010). The 
latter involves biological, psychological, social and environmental factors, leading to survival and the process of daily learning, which will depend on the integral health of the person. If there is any emotional disturbance, this learning may be compromised. The occurrence of any changes in cognitive, emotional and/or behavioral development may generate an impulse of culpability; of the parents towards the child and of third parties towards the parents; however, the problem to be faced encompasses several spheres of the patient's reality, among them genetics, neurons, synapses, neurotransmitters, environments of coexistence such as school, neighborhood and public social and health policies (Eickmann, Emond, \& Lima, 2016).

Still according to Eickmann, Emond, \& Lima (2016), "mental health is the fundamental basis for achieving all other human development skills. There is clear evidence that early psychomotor stimulation helps in the development of cognitive skills that are essential for learning; knowing this, it is considered that the future of a community depends on its plans for the development of the next generations. In another scenario, if there is a high prevalence of mental disorders, as is the case of childhood depression, the development is impaired, as is the learning process.

On the impact of mental health care in childhood, especially on the responsibility of the family environment in your home, emerges the concept of Sensory Integration. According to Serrano (2016), Sensory Integration is the neurological segment that organizes our sensations, considered the foundation of all forms of learning so that we can experience the world and thus make sense. It is the support for academic learning and necessary skills for the execution of daily and social activities, including the development of affection capacity in relation to others. What we see, smell, hear, taste or touch is deciphered at every moment in our experience of living, simultaneously with our "secret senses": vestibular and proprioceptive. When the child has problems in the processing of sensations (sensory integration dysfunction) he/she has difficulty in using the knowledge received by the senses to efficiently perform the tasks of daily life-being able to develop motor coordination problems, difficulties in the regulation of sleep, food, concentration, performance of self-care tasks, learning, entertainment and in their emotional and social development.

For Nobukuni (2017), in the educational method, there is a relationship between the being who learns (the apprentice) and the being who directs the learning (the master); in this way, the educator must understand the particular and unique being who is the lecturer, that is, he or she must cover in a certain way the elements that culminated in the development of this individual. In order to do so, it is essential that the teacher initially take as a premise the objectives that encompass the subject's creation as a social being; thus, one has the objectives themselves (which have the goal to provide the needs for survival) and the objectives for oneself (a product of human activity that is condensed into the various fields of knowledge). The cultural universe imposes a great convenience on the 
creation of objectives to adapt to the evolved world, which results in progress and superior psychological increment in the child.

\subsection{Diagnosis of Depression in Childhood}

Among the most common and prevalent public health problems we can mention depression. This can present itself as a symptom of some pathology, or as a complex disease, which can cause numerous sequelae to its carrier. Thus, the correct management of the patient is of great value for the diagnosis and prognosis of the same, since several differential diagnoses can be reached. In the pediatric age groups such clinical approach is even more challenging, because children have difficulty in expressing their feelings through words, in such way that a more accurate behavioral evaluation is necessary, so that changes suggestive of depressive conditions can be noticed. One way to evaluate the child and his behaviors is to ask him to make some drawings, which allow the knowledge of his fantasies and his imaginative capacity, besides demonstrating his mood through the themes and colors chosen for the drawing. In psychiatric evaluations, qualified listening is important, in order to unite the information collected from the child, his parents and/or guardians, his school and all the social environment to which the child is inserted (Lima et al., 2013; Maughan et al., 2013; Mullen, 2018).

Sometimes, the educator is the first to perceive changes in conduct and behavior of the child, this Professional can be a great ally in the early diagnosis of psychiatric pathologies in childhood. The school is the place where the experiences and social demands of the child are initiated, demanding from them the social integration and the development of physical and emotional abilities, in such a way that, in case there is some previous psychic/emotional damage, the school context can become a source of frustrations and still be the place for the appearance of problems that were obscured in the protective family environment (Pinheiro et al, 2017; Wichstrom et al., 2012).

During the anamnesis the doctor must pay attention to clinical and daily aspects that serve as predictors of depressive syndromes. Among them we can mention changes in eating habits, such as hyperphagia or anorexia, and changes in sleeping habits, such as tiredness throughout the day, insomnia and poor sleep. Mood alterations are the most characteristic of depressive conditions; presenting in the pediatric age group, more frequently, as a dysphoric mood (irritability, boredom and aggressiveness in social relationships), especially in the relationship with parents, siblings and colleagues. Other complaints that can be brought to the consultation are the psychomotor agitation and difficulty of concentration, which can reflect in difficulty of socialization and school development. It is also necessary to analyze the triggering factors of the current depressive situation, since it arises from several factors, including genetics, troubled family group and constant stress situations (physical abuse, emotional abuse, among others) (Maughan et al., 2013; Perou et al., 2013; Abaid et al., 2010). 
Today, to assist in the accurate diagnosis of Child Depression, professionals can rely on the Child Depression Inventory (CDI), International Classification of Diseases (ICD-11) and the Diagnostic and Statistical Manual of Mental Disorders (DSM-V), the first two being the most used in psychiatric practice. The CDI was presented by Kovacs in 1983, the first instrument designed to study the symptoms of depression in childhood. It consists of a self-assessment scale with 27 items, in order to identify the depressive symptoms in individuals from 7 to 17 years old and has been widely used since then (Gaebel et al., 2020; Stein et al., 2020).

The DSM-V (2013) is a reference for psychiatric diagnoses, and knowledge of its criteria for the diagnosis of depressive disorders is essential. According to DSM-V, these constitute a group of psychiatric illnesses (Table 1), all of which are characterized by dysphoria, among them we can mention:

Unipolar Major Depression: is characterized by one or more severe depressive episodes with no history of mania or hypomania. As long as the symptoms cause significant suffering and/or bring consequences to the social and personal life of the individual. The clinical situation cannot be attributed to the use of any substance and/or other medical condition. However, a diagnosis of a severe depressive episode is first necessary, so the patient must have presented 5 or more of the following symptoms within a period of two weeks, at least one of them being dysphoria or anhedonia (lack of pleasure) (Chirita et al., 2015; APA, 2013; Mullen, 2018):

- Disphoria most of the day;

- Accentuated anhedonia most of the day in daily life activities;

- Significant weight loss or gain without being on a diet;

- Insomnia;

- Agitation;

- Fatigue almost every day;

- Feeling of uselessness or inappropriate guilt;

- Diminished ability to think;

- Recurring thoughts of death, suicidal ideation.

Disruptive Humor Disorder: for its diagnosis it is necessary that the symptoms be present for at least 12 months, without an interruption of the symptoms for three consecutive months. In addition, all of the following criteria must be met (APA, 2013):

- Feeling of rage recurrent and manifested by language or behavior, disproportionate to the situation or provocation, being inconsistent with the level of development and occurring at least 3 times a week. The mood between these explosive pictures is persistently irritable most of the day and can be observed before the age of 10 ;

- The symptoms are present in at least two environments (school, home, family home, etc.)

- The diagnosis should not be made before the age of 6 or after the age of 18 ;

- Criteria of mania or hypomania cannot be present (except duration); 
Table 1. Psychiatric disorders and theirs symptoms (conforming to the DSM-V).

\begin{tabular}{|c|c|}
\hline Psychiatric Disorders & Symptoms \\
\hline Unipolar Major Depression & $\begin{array}{l}5 \text { or more of the following symptoms within a period of two weeks, a } \\
\text { least one of them being dysphoria or anhedonia: } \\
\text { - Disphoria most of the day; } \\
\text { - Accentuated anhedonia most of the day in daily life activities; } \\
\text { - Significant weight loss or gain without being on a diet; } \\
\text { - Insomnia; } \\
\text { - Agitation; } \\
\text { - Fatigue almost every day; } \\
\text { - Feeling of uselessness or inappropriate guilt; } \\
\text { - Diminished ability to think; } \\
\text { - Recurring thoughts of death, suicidal ideation. }\end{array}$ \\
\hline
\end{tabular}

Disruptive Humor Disorder The symptoms be present for at least 12 months:

- Feeling of rage recurrent and manifested by language or behavior, disproportionate to the situation or provocation, being inconsistent with the level of development and occurring at least 3 times a week;

- The symptoms are present in at least two environments (school, home, family home, etc.)

- The diagnosis should not be made before the age of 6 or after the age of 18;

- Criteria of mania or hypomania cannot be present (except duration);

- - Symptoms do not appear only during episodes of major depression, and are not explained by other disorders or effects of substances.

Persistent Depressive

Disorder

Minor Depression

Drug-induced Depression

Disorder
The irritable mood during most of the day, almost daily, in a minimum period of 1 year associated with two or more of the following symptoms:

- Insomnia or Hypersomnia;

- Fatigue;

- Low self-esteem;

- Increased or decreased appetite;

- - Difficulty concentrating.

Two depressive symptoms, where at least one is dysphoria or anhedonia, causing personal or professional loss.

- The mood change precedes the intoxication by the substance;

- The disorder is maintained for a long period after the use of the drug (approximately one month);

- The disorder occurs only during an episode of delirium;

- - There is a previous history of recurrent depressive episodes.

Depressive disorder triggered Individuals who have symptoms characteristic of a depressive by another pathology condition, however, when analyzing the anamnesis and physical examination, it is perceived that such change is being caused by another disease, so that there are coincidences between the two conditions, such as start time, periods of exacerbation and remission. 
- Symptoms do not appear only during episodes of major depression, and are not explained by other disorders or effects of substances.

Persistent Depressive Disorder (Dystimia): for its diagnosis in the pediatric age group it is necessary the presence of irritable mood during most of the day, almost daily, in a minimum period of 1 year. In addition, it is necessary to bring social consequences for the individual, not to close criteria for episodes of mania or hypomania and be associated with two or more of the following symptoms (APA, 2013):

- Insomnia or Hypersomnia;

- Fatigue;

- Low self-esteem;

- Increased or decreased appetite;

- Difficulty concentrating.

Minor Depression: a minor disorder than the major depression, and its diagnostic criteria include two depressive symptoms, where at least one is dysphoria or anhedonia, causing personal or professional loss. It is worth noting that Minor Depression, if not diagnosed and treated, may develop into Major Depression (APA, 2013).

Drug-induced Depression Disorder: consists of a persistent mood alteration, in which dysphoria or anhedonia are the main symptoms. This mood alteration coincides with the use of certain licit or illicit substances, such as cocaine, opiates, corticosteroids and isotretinoin. However, the presence of the following signs and symptoms is still necessary for the diagnosis (APA, 2013):

- The mood change precedes the intoxication by the substance;

- The disorder is maintained for a long period after the use of the drug (approximately one month);

- The disorder occurs only during an episode of delirium;

- There is a previous history of recurrent depressive episodes.

Depressive disorder triggered by another pathology: this classification is used to group individuals who have symptoms characteristic of a depressive condition, however, when analyzing the anamnesis and physical examination, it is perceived that such change is being caused by another disease, so that there are coincidences between the two conditions, such as start time, periods of exacerbation and remission. Examples of pathologies that can trigger depressive conditions are Multiple Sclerosis, Hypercortisolism and Systemic Lupus Erythematosus (APA, 2013; Chirita et al., 2015; Szigethy et al., 2015).

According to the DSM-V there are two more classifications, being the "Inspecific Depression Disorder" which consists of individuals with depressive condition with impact on quality of life, but without sufficient symptoms to fit the criteria of some depressive pathology specified above. And the "Other Specific Depressive Disorder" which is characterized by depressive conditions that have almost all the criteria to fit any of the above classifications, but cannot be fitted as the respective pathology because it does not meet only 1 of the requested cri- 
teria.

The International Classification of Diseases (ICD-11) also presents criteria for the diagnosis of depressive syndromes, but a little different from the way approached by DSM-V. In the chapter "Mental, Behavioural or Neurodevelopmental Disorders", in ICD-11, several disorders were included that, theoretically and questionably, start in childhood and adolescence. For example, the mood disorders (which includes, among other mental involvement, depressive disorders) were also placed in this set, because, according to etiological theories, they believe that their origin is related to neurobiological causes, such as processes linked to inflammatory physiology. In this sense, the fact of this new approach of ICD-11 was criticized, claiming that the limits between the origin of the disorders (i.e., whether they start in neurodevelopment or not) are not very clear (Stein et al., 2020).

The International Classification of Diseases (ICD-11) also presents criteria for the diagnosis of depressive syndromes, but a little different from the way approached by DSM-V. In the chapter "Mental, Behavioural or Neurodevelopmental Disorders", in ICD-11, several disorders were included that, theoretically and questionably, start in childhood and adolescence. For example, the mood disorders (which includes, among other mental involvement, depressive disorders) were also placed in this set, because, according to etiological theories, they believe that their origin is related to neurobiological causes, such as processes linked to inflammatory physiology. In this sense, the fact of this new approach of ICD-11 was criticized, claiming that the limits between the origin of the disorders (i.e., whether they start in neurodevelopment or not) are not very clear (Stein et al., 2020).

It is also important to emphasize that, unlike ICD-10 (which asked for a minimum number of four depressive symptoms), in ICD-11, there must be five or more symptoms of this nature to be considered a depressive episode, during most of the day, for at least 2 weeks. Among such symptoms, a total of 10 bring depressive moods; marked decrease in interest or pleasure in activities; reduced power of concentration or maintenance of attention or marked difficulty in making decisions; low self-esteem or excessive or inadequate guilt; lack of hope for the future; frequent thoughts of death or ideation or suicide attempt; significant disturbances in sleep or excessive sleep; changes in appetite or weight; agitation or psychomotor retardation; and decrease in energy or fatigue. Depending on the number of episodes, as well as the intensity of how they occur (i.e., whether they are medium, moderate or severe) (Stein et al., 2020), a gradual range of depression disorders is created, thus characterizing its new dimensional approach (which brings it closer to DSM) (Gaebel et al., 2020; Stein et al., 2020).

\subsection{Treatment of Depression in Childhood}

After the diagnosis of the pathology the individual is suffering from, the appropriate therapy must be initiated. A psychological or pharmacological approach or a combination of both can be chosen. What cannot be forgotten is that de- 
pression has multifactorial causes and for its treatment it is necessary that the therapeutic approach covers all the means to which the individual relates (Lima et al., 2013; Katzung, Masters, \& Trevor, 2012).

The treatment has its beginning with the establishment of the relationship of trust between the professional, the patient and their relatives (parents and guardians) associated with the analysis of the severity of the depressive condition, so that the mild and moderate can be managed, initially, with the psychotherapy alone, already in the severe conditions there is need for association with the pharmacological therapy. It should be noted that in patients with Unipolar Major Depression in pediatric age, $60 \%$ - $90 \%$ of patients treated reach remission in about one year with very frequent recurrences throughout life (Thapar et al., 2012; Katsuki et al., 2014).

Psychotherapy encompasses numerous approaches such as Cognitive Behavioral Therapy (CBT), Psychodynamic Psychotherapy, Interpersonal Therapy, Support Psychotherapy, Behavioral Therapy, Group Therapy and Family Therapy. CBT is the most studied of these and seeks to correct situations that may contribute to the development and perpetuation of childhood depression. A type of therapy of great value is also the psychodynamic psychotherapy, which helps children in self-knowledge and self-acceptance, improving their self-esteem and the identification of behaviors that improve their interpersonal interaction and minimize dysphoric symptoms (Katsuki et al., 2014).

Pharmacotherapy in the pediatric age group is a challenge independent of the medical area of scope, being in the same way in psychiatry. There are still few studies that extensively test psychotropic drugs in this age group, in order to provide efficacy and safety data with a high degree of reliability. However, since clinical studies demonstrate the need for drugs to support the treatment of severe depression, this option should be used (Katzung, Masters, \& Trevor, 2012).

For children one of the most used drug classes is the Selective Serotonin Recaptation Inhibitors (SSRI), like Fluoxetine. This drug has a low lethality rate and good clinical results in this age group, superior to Tricyclic Antidepressants, which are the second most used class. As an example of these we can mention amitriptyline, however it has important adverse effects, especially when used in childhood, as constipation and risk of anti-muscarinic syndrome. Thus, one should give preference to SSRI and always pay attention to the recommended dosage for age and pathology, which are recommended by the laboratory (Gibbons et al., 2012; Hazell \& Mirzaie, 2013).

\subsection{Child Depression and Learning}

Vasconcelos et al. (2015) found several physical, psychological and social commitments of depressive disorders, which affect academic performance and learning in general. In children this fact is further aggravated due to the peculiarities of this age group and life cycle; at this age the child comes into contact with numerous sensory, perceptive, affective and motor stimuli, which facilitate 
their socialization process, cognitive, intellectual progress and social and cultural interaction. However, in case of suffering from depression, all these components, essential for neuropsychomotor development, can be impaired and interfere in their learning process (Eickmann, Emond, \& Lima, 2016).

The learning process involves both biological referentials, such as food and sleep, psychological as affections and bonds, social with games and cultural as the fantasy of fairy tales. Depression can lead to excessive daytime sleepiness and/or insomnia at night, and with this, the production of the growth hormone $(\mathrm{GH})$ is compromised; as well as, it can diminish the appetite and the infantile taste, being able to evolve to malnutrition. The $\mathrm{GH}$ is produced $80 \%$ of it during sleep, as well as the memory is solidified when sleeping. It is reinforced here that memorization is an indispensable process for the acquisition and fixation of new knowledge. On the other hand, food is primordial for the body and the brain, taking into account that this organ feeds $12 \%$ more on oxygen, glucose, among others, during sleep than during vigil. If depression compromises the child's nutrition, sleep and ability to focus and attention, the child will not be able to adequately fix new contents and nor evoke others already acquired (Lima \& Mosmann, 2020).

Among the depressive symptoms in childhood can occur unstable mood, sometimes hypotymic, difficulty in affective bonds and socialization as in the process of play, which is essential to the imagination and to the children's fantasy. Learning is much more appropriate and healthier if it is motivating, meaningful and socialized, with no negative, pessimistic or ruinous content that compromises it (Pino, 2010).

\section{Conclusion}

Childhood is an extremely important stage in the life cycle for learning new knowledge, as well as fixing others; as well, many of the processes of skills development and other psychic functions are acquired and solidified during this age group. When some disorder affects the integral neuropsychomotor evolution of the child, there may be a delay in learning, as for example in the case of childhood depression. This disease affects cognitive, affective, intellectual, reasoning, memory and psychomotor activities, causing the child to have evolutionary and interactive difficulties. Therefore, knowing this, that children are in a sensitive age group and that any mental disorder (for example, depression) can affect their neuropsychomotor development and learning process, it is essential for a society to take a careful look at this population, in order to minimize educational and social losses in the medium and long term.

\section{Conflicts of Interest}

The authors declare no conflicts of interest regarding the publication of this paper.

\section{References}

Abaid, J. L. W., Dell, D. D., \& Koller, S. H. (2010). Preditores de sintomas depressivos em 
crianças e adolescentes institucionalizados. Universitas Psychologica, 9, 199-212.

American Psychiatric Association (APA) (2013). Diagnostic and Statistical Manual of Mental Disorders (5th ed., DSM-5). Arlington, VA: American Psychiatric Publishing. https://doi.org/10.1176/appi.books.9780890425596

Bernaras, E., Jaureguizar, J., \& Garaigordobil, M. (2019). Child and Adolescent Depression: A Review of Theories, Evaluation Instruments, Prevention Programs, and Treatments. Frontiers in Psychology, 10, 543. https://doi.org/10.3389/fpsyg.2019.00543

Chirita, A. L., Gheorman, V., Bondari, D., \& Rogoveanu, I. (2015). Current Understanding of the Neurobiology of Major Depressive Disorder. Romanian Journal of Morphology and Embryology, 56, 651-658.

de Souza, J. M., \& Veríssimo, M. D. L. Ó. R. (2015). Desenvolvimento infantil: Análise de um novo conceito. Revista Latino-Americana de Enfermagem, 23, 1097-1104. https://doi.org/10.1590/0104-1169.0462.2654

Eickmann, S. H., Emond, A. M., \& Lima, M. (2016). Evaluation of Child Development: Beyond the Neuromotor Aspect. Jornal de Pediatria, 92, S71-S83.

https://doi.org/10.1016/j.jped.2016.01.007

Gaebel, W., Stricker J., \& Kerst, A. (2020). Changes from ICD-10 to ICD-11 and Future Directions in Psychiatric Classification. Dialogues in Clinical Neuroscience, 22, 7-15. https://doi.org/10.31887/DCNS.2020.22.1/wgaebel

Gibbons, R. D., Hur, K., Brown, C. H., Davis, J. M., \& Mann, J. J. (2012). Benefits from Antidepressants: Synthesis of 6-Week Patient-Level Outcomes from Double-Blind Placebo-Controlled Randomized Trials of Fluoxetine and Venlafaxine. Archives of General Psychiatry, 69, 572-579. https://doi.org/10.1001/archgenpsychiatry.2011.2044

Gomes, L. P., Baron, É., Albornoz, A. C. G., \& Borsa, J. C. (2013). Inventário de depressão infantil (CDI): Uma revisão de artigos científicos brasileiros. Contextos Clínicos, 6, 95-105. https://doi.org/10.4013/ctc.2013.62.03

Hazell, P., \& Mirzaie, M. (2013). Tricyclic Drugs for Depression in Children and Adolescents. Cochrane Database of Systematic Reviews, No. 6. https://doi.org/10.1002/14651858.CD002317.pub2

Katsuki, F., Takeuchi, H., Watanabe, N., Shiraishi, N., Maeda, T., Kubota, Y., Suzuki, M., Yamada, A., \& Akechi, T. (2014). Multifamily Psychoeducation for Improvement of Mental Health among Relatives of Patients with Major Depressive Disorder Lasting More than One Year: Study Protocol for a Randomized Controlled Trial. Trials, 15, Article No. 320. https://doi.org/10.1186/1745-6215-15-320

Katzung, B. G., Masters, S. B., \& Trevor, A. J. (2012). Basic and Clinical Pharmacology 12/E. New York: McGraw-Hill Medical.

Lima, M. O. F. F., \& Mosmann, L. K. S. C. P. (2020). Instrumentos de avaliação da depressão infantil: Revisão integrativa da literatura. Revista Brasileira de Psicoterapia, 22, 53-69.

Lima, N. N., do Nascimento, V. B., de Carvalho, S. M., de Abreu, L. C., Neto, M. L., Brasil, A. Q., Junior, F. T., de Oliveira, G. F., \& Reis, A. O. (2013). Childhood Depression: A Systematic Review. Neuropsychiatric Disease and Treatment, 9, 1417-1425. https://doi.org/10.2147/NDT.S42402

Maciel, M. R., Martins, K. P. H., Pascual, J. G., \& Filho, O. N. M. (2016). A infância em Piaget e o infantil em Freud: temporalidades e moralidades em questão. Psicologia Escolar e Educacional, 20, 329-338. https://doi.org/10.1590/2175-353920150202975

Maughan, B., Collishaw, S., \& Stringaris, A. (2013). Depression in Childhood and Adolescence. Journal of the Canadian Academy of Child and Adolescent Psychiatry = Journal de l'A cademie canadienne de psychiatrie de l'enfant et de l'adolescent, 22, 35-40. 
Mullen S. (2018). Major Depressive Disorder in Children and Adolescents. The Mental Health Clinician, 8, 275-283. https://doi.org/10.9740/mhc.2018.11.275

Nobukuni, A. R. M. (2017). As implicações das teorias de Vygotsky na educação: A mediação no pocesso do desenvolvimento infantil.

Perou, R., Bitsko, R. H., Blumberg, S. J., Pastor, P., Ghandour, R. M., Gfroerer, J. C., \& Huang, L. N. (2013). Mental Health Surveillance among Children-United States, 2005-2011. MMWR Supplements, 62, 1-35.

Petresco, S., Anselmi, L., Santos, I. S., Barros, A. J., Fleitlich-Bilyk, B., Barros, F. C., \& Matijasevich, A. (2014). Prevalence and Comorbidity of Psychiatric Disorders among 6-Year-Old Children: 2004 Pelotas Birth Cohort. Social Psychiatry and Psychiatric Epidemiology, 49, 975-983. https://doi.org/10.1007/s00127-014-0826-Z

Pinheiro, M. N., Sousa, W. D. C., Feitosa, J. R. T., \& Batista, E. C. (2017). Identificação e compreensão de sintomas depressivos na infância em contexto escolar: Desafios contemporâneos do educador. Pedagógica: Revista do Programa de Pós-Graduaçao em Educaçao-PPGE, 19, 155-171. https://doi.org/10.22196/rp.v19i40.3748

Pino, A. (2010). A criança e seu meio: Contribuição de Vigotski ao desenvolvimento da criança e à sua educação. Psicologia USP, 21, 741-756.

https://doi.org/10.1590/S0103-65642010000400006

Polanczyk, G. V., Salum, G. A., Sugaya, L. S., Caye, A., \& Rohde, L. A. (2015). Annual Research Review: A Meta-Analysis of the Worldwide Prevalence of Mental Disorders in Children and Adolescents. Journal of Child Psychology and Psychiatry, and Allied Disciplines, 56, 345-365. https://doi.org/10.1111/jcpp.12381

Rother, E. T. (2007). Revisão sistemática X revisão narrativa. Acta Paulista de Enfermagem, 20, 5-6. https://doi.org/10.1590/S0103-21002007000200001

Serrano, P. (2016). A integração sensorial no desenvolvimento e aprendizagem da criança. Lisboa: Papa-Letras.

Stein, D. J., Szatmari, P., Gaebel, W., Berk, M., Vieta, E., Maj, M., de Vries, Y. A., Roest, A. M., de Jonge, P., Maercker, A., Brewin, C. R., Pike, K. M., Grilo, C. M., Fineberg, N. A., Briken, P., Cohen-Kettenis, P. T., \& Reed, G. M. (2020). Mental, Behavioral and Neurodevelopmental Disorders in the ICD-11: An International Perspective on Key Changes and Controversies. BMC Medicine, 18, Article No. 21.

https://doi.org/10.1186/s12916-020-1495-2

Szigethy, E., Youk, A. O., Gonzalez-Heydrich, J., Bujoreanu, S. I., Weisz, J., Fairclough, D., Ducharme, P., Jones, N., Lotrich, F., Keljo, D., Srinath, A., Bousvaros, A., Kupfer, D., \& DeMaso, D. R. (2015). Effect of 2 Psychotherapies on Depression and Disease Activity in Pediatric Crohn's Disease. Inflammatory Bowel Diseases, 21, 1321-1328. https://doi.org/10.1097/MIB.0000000000000358

Thapar, A., Collishaw, S., Pine, D. S., \& Thapar, A. K. (2012). Depression in Adolescence. The Lancet (London, England), 379, 1056-1067. https://doi.org/10.1016/S0140-6736(11)60871-4

Vasconcelos, T. C. D., Dias, B. R. T., Andrade, L. R., Melo, G. F., Barbosa, L., \& Souza, E. (2015). Prevalência de sintomas de ansiedade e depressão em estudantes de medicina. Revista Brasileira de Educação Médica, 39, 135-142. https://doi.org/10.1590/1981-52712015v39n1e00042014

Wichstrom, L., Berg-Nielsen, T. S., Angold, A., Egger, H. L., Solheim, E., \& Sveen, T. H. (2012). Prevalence of Psychiatric Disorders in Preschoolers. Journal of Child Psychology and Psychiatry, 53, 695-705. https://doi.org/10.1111/j.1469-7610.2011.02514.x 